\title{
Review of Distal Embolism with Original Respect to Filters for Carotid Artery Stenting
}

Kentaro Hayashi, Yuki Matsunaga, Yukishige Hayashi, Kiyoshi Shirakawa, and Mitsuto Iwanaga

Objective: Carotid artery stenting is performed using a device for preventing distal embolism because vasodilationrelated debris may cause cerebral infarction. Concerning filters for preventing embolism, membrane-type filters have been used, but mesh-type filters became commercially available. We have selected filter-assisted stenting as a first-choice procedure. We examined post-treatment filters under a microscope, and reviewed the pathogenesis of distal embolism.

Methods: The subjects were 83 patients in whom carotid artery stenting with a filter was performed, and filters could be examined after surgery (Angioguard XP [AG; Cordis Corporation, Miami Lakes, FL, USA]: 25 patients, Filterwire EZ [FW; Boston Scientific, Natick MA, USA]: 32, and Spider FX [Spider; Covidien, Dublin, Ireland]: 26). After treatment, the filters were stained with hematoxylin and eosin (HE), separated from the struts, and embedded in preparations for microscopic observation. Debris was classified into plaque-derived and fibrin-formation types, and quantified as an area using computer software. Distal embolism was evaluated based on intraoperative flow impairment, postoperative symptoms, and perioperative diagnostic imaging findings.

Results: Intraoperative flow impairment was noted in six patients (24\%) in the AG group, five (15.6\%) in the FW group, and one (3.8\%) in the Spider group. Cerebral infarction was observed in three (12\%), two (6.3\%), and two (7.6\%) patients, respectively. There were no differences in the volume of plaque-derived debris, but the volume of fibrin-formation-type debris was more in the AG group. As a result, the volume of debris collected was more. In the Spider group, the volume of fibrin-formation-type debris was minimum.

Conclusion: Functions differed between the membrane-type and mesh-type filters. Considering their performance, these filters should be used.

Keywords > carotid artery stenting, debris, protection filter, embolism

\section{Introduction}

For carotid artery stenting, a procedure to prevent distal embolism during surgery is necessary, as cerebral embolism related to debris, which appears during treatment, is the most frequent complication. ${ }^{1,2)}$ Initially, obliteration with a balloon, as a device for preventing distal embolism,

Department of Neurosurgery, Sasebo City General Hospital, Sasebo, Nagasaki, Japan

Received: March 27, 2018; Accepted: July 8, 2018

Corresponding author: Kentaro Hayashi. Department of Neurosurgery, Sasebo City General Hospital, 9-3 Hirase-machi, Sasebo, Nagasaki 857-8511, Japan

Email: kentaro@hospital.sasebo.nagasaki.jp

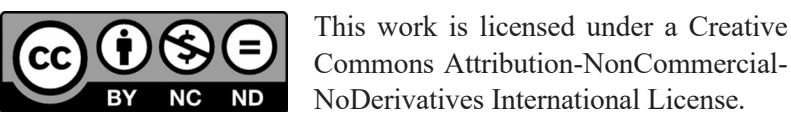

(C)2019 The Japanese Society for Neuroendovascular Therapy had been performed. ${ }^{3)}$ However, since the introduction of filters, treatment has been conducted using a filter. ${ }^{4}$ In Japan, membrane-type filters, Angioguard XP (AG; Cordis Corporation, Miami Lakes, FL, USA), and Filterwire EZ (FW; Boston Scientific, Natick MA, USA), have been used. Recently, a mesh-type filter, Spider FX (Spider; Covidien, Dublin, Ireland), became commercially available. We have been examined posttreatment filters under a microscope, $, 5,6)$ and reviewed the pathogenesis of distal embolism based on intraoperative flow impairment, postoperative symptoms, and perioperative diagnostic imaging findings.

\section{Methods}

Of 110 patients who underwent carotid artery stenting, the subjects were 83 in whom this procedure was performed using a filter, and the filter could be examined after surgery (AG: 25 patients, FW: 32, and Spider: 26). Before surgery, 
A

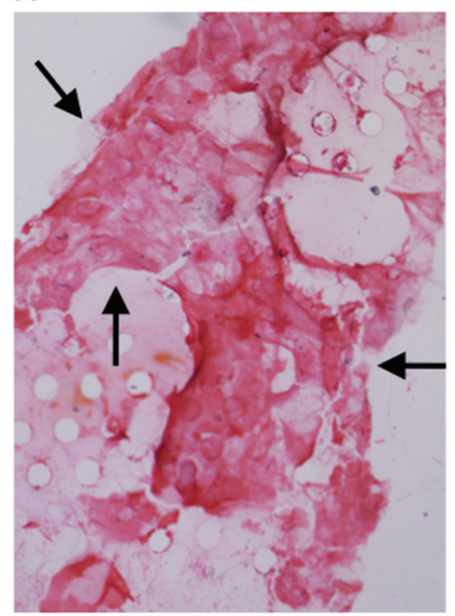

B

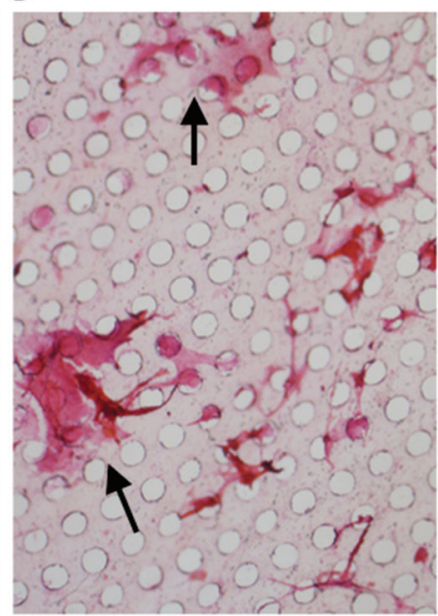

C

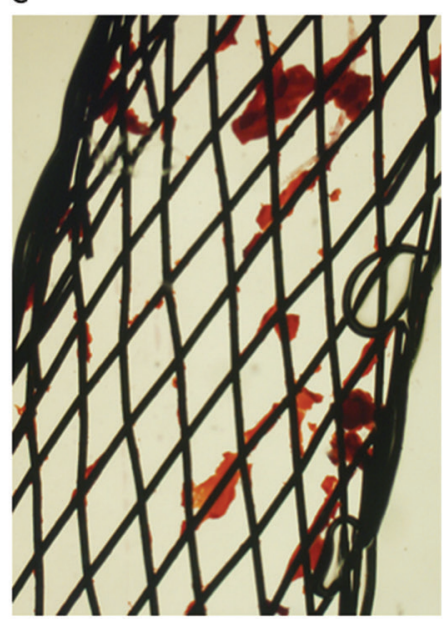

Fig. 1 Microscopical observation of the filter the fibrin precipitation-dominant part. (A) Angioguard XP (Cordis Corporation, Miami Lakes, FL, USA), (B) Filterwire EX (Boston Scientific, Natick MA, USA), and (C) Spider FX (Covidien, Dublin, Ireland). Fibrin precipitation (arrows) is observed more in the Angioguard XP and is less in the Filterwire EZ. It is much less in the Spider FX.

Table 1 Summary of performance of the embolus protection filters

\begin{tabular}{lccc} 
& Angioguard XP & Filterwire EZ & Spider FX $(5 \mathrm{~mm})$ \\
Pore size $(\mu \mathrm{m})$ & 100 & 110 & $70-200$ \\
Pore number & 1100 & 2576 & Mesh \\
Pore density $\left(/ \mathrm{mm}^{2}\right)$ & 26 & 40 & Mesh \\
Filter area $\left(\mathrm{cm}^{2}\right)$ & 0.59 & 1.48 & 1.31 \\
Filter volume $(\mu \mathrm{L})$ & 20 & 80 & 80 \\
Size variation $(\mathrm{mm})$ & $4,5,6,7,8$ & One size $(3.5-5.5 \mathrm{~mm})$ & $4,5,6,7$ \\
\hline Angioguard XP: Cordis Corporation, Miami Lakes, FL, USA; Filterwire EX: Boston Scientific, Natick MA,
\end{tabular}

the properties of plaque were evaluated using high-resolution MRI and vascular ultrasonography.

Prior to carotid artery stenting, two antiplatelet drugs were orally administered. After an $8 \mathrm{Fr}$ sheath was inserted, heparinization was conducted; 3000 units were intravenously injected, and, if necessary, an additional dose was administered so that the activated clotting time (ACT) was $\geq 250$ seconds. A filter was inserted, and stenotic lesions were assessed using intravascular ultrasound. Predilation was performed at 4-6 atmospheric pressures using a balloon catheter measuring $4 \mathrm{~mm}$ in diameter, and a stent was inserted. After confirming the degree of dilation using intravascular ultrasound, postdilation was conducted using a balloon catheter measuring $5 \mathrm{~mm}$ in diameter when the minimum diameter was $<3 \mathrm{~mm}$. Plaque deviation was also evaluated. At the site of puncture, a hemostatic device was used. Filter options depended on the timing of introduction; in the initial phase, only an AG was used. After January 2011, an FW was adopted. After March 2014, a Spider was selected. Concerning stent selection, open-cell stents alone were used during the
AG period, and, subsequently, closed-cell stents were basically selected. However, when lesions were markedly curved, open-cell stents were selected. In the AG group, open-cell stents were used in all 25 patients. In the FW group, closed-cell stents were used in 29 patients, and open-cell stents in three patients. In the Spider group, closed-cell stents were used in 22 patients, and open-cell stents in four patients.

After use, the filters were stained with hematoxylin and eosin (HE), separated from the struts, and embedded in preparations for microscopic observation. ${ }^{4}$ The filter area and volume were measured. With respect to the membranetype filters, the pore density was determined. Debris was classified into two types: atherosclerosis-derived debris and fibrin. Respective amounts were input to Adobe Photoshop CS (Adobe Systems Incorporated, San Jose, CA, USA) and quantified as areas. ${ }^{5}$ )

The data are expressed as the mean. Univariate analysis was conducted using JMP10.0 software (SAS Institute Inc., Cary, NC, USA). A p value of 0.05 was regarded as significant. 


\begin{tabular}{|l|l|l|}
\hline & $\begin{array}{l}\text { Flow } \\
\text { impairment+ }\end{array}$ & $\begin{array}{l}\text { Flow } \\
\text { impairment- }\end{array}$ \\
\hline Infarction+ & & \\
\hline Infarction- & & \\
\hline
\end{tabular}

\section{Flow impairment}

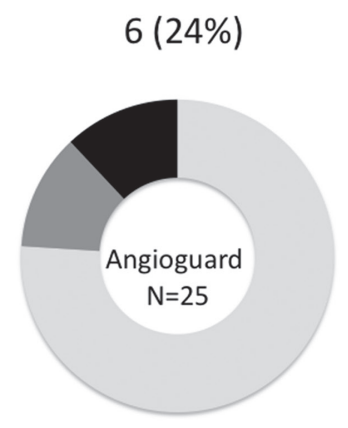

$3(12.0 \%)$
$5(15.6 \%)$

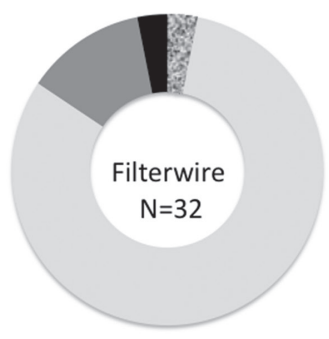

$2(6.3 \%)$
$1(3.8 \%)$

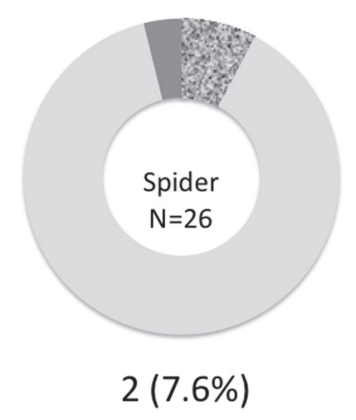

Ischemic stroke

Fig. 2 Incidence and relationship of the intraoperative flow impairment and the ischemic stroke. Flow impairment is significantly more in the Angioguard XP and related to the ischemic stroke. Angioguard: Angioguard XP, Cordis Corporation, Miami Lakes, FL, USA; Filterwire: Filterwire EX, Boston Scientific, Natick MA, USA; Spider: Spider FX, Covidien, Dublin, Ireland

\section{Results}

The results of filter observation are shown in Fig. 1. The performance of the filters is summarized in Table 1. The filter surface areas of an AG, FW, and Spider (measuring $5 \mathrm{~mm}$ in diameter) were $0.59,1.48$, and $1.31 \mathrm{~cm}^{2}$, respectively. Their volumes were 20,80 , and $80 \mu \mathrm{L}$, respectively. The structures of an AG and FW, as membrane-type filters, consisted of polyurethane membrane with pores prepared using a laser. The pore diameters were 100 and $110 \mu \mathrm{m}$, respectively. The pore density was 26 and 40 pores $/ \mathrm{mm}^{2}$, respectively. Concerning the Spider, the mesh size was $70 \mu \mathrm{m}$ at the center and $200 \mu \mathrm{m}$ at the periphery; there was a difference related to mesh opening.

Intraoperative flow impairment was noted in six patients (24\%) in the AG group, five (15.6\%) in the FW group, and one $(3.8 \%)$ in the Spider group. Cerebral infarction was observed in three $(12 \%)$, two $(6.3 \%)$, and two $(7.6 \%)$ patients, respectively. In the three patients in the AG group and in one of the two patients in the FW group, intraoperative flow impairment was noted, but not in the two patients in the Spider group (Fig. 2).

The total volume of debris collected in the AG, FW, and Spider groups was $0.241,0.129$, and $0.073 \mathrm{~cm}^{2}$, respectively. The atherosclerosis-derived debris volume (as a percentage

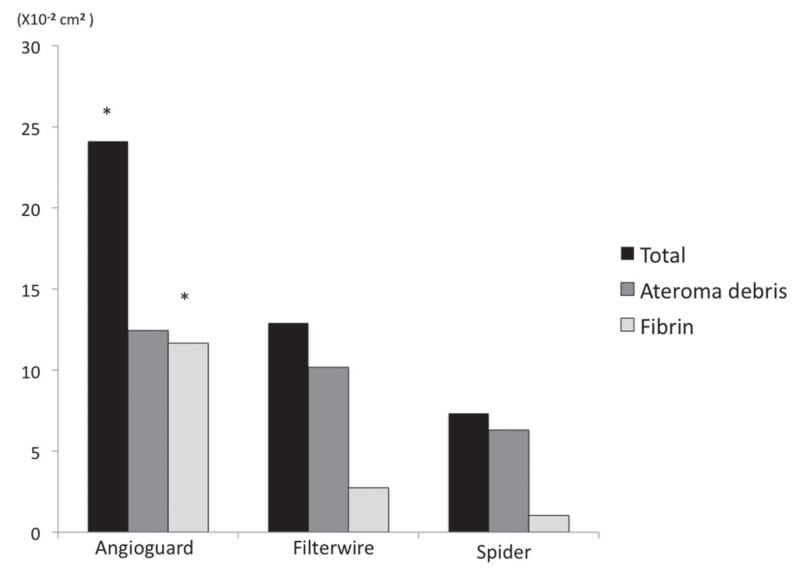

Fig. 3 Quantitative analysis of the captured debris. The fibrin precipitation is measured significantly more in the Angioguard XP and it is affected to the total amount of debris. Angioguard: Angioguard XP, Cordis Corporation, Miami Lakes, FL, USA; Filterwire: Filterwire EX, Boston Scientific, Natick MA, USA; Spider: Spider FX, Covidien, Dublin, Ireland

of the total volume) was $0.124(51.5 \%), 0.102$ (79.1\%), and $0.063(86.3 \%) \mathrm{cm}^{2}$, respectively. The fibrin volume was $0.117(48.5 \%), 0.027(20.9 \%)$, and $0.010(13.7 \%) \mathrm{cm}^{2}$, respectively. There were no differences in the plaque-derived debris volume, but fibrin formation was more in the AG group. As a result, the volume of debris collected was also more (Fig. 3). In the Spider group, fibrin formation was only slightly observed. 
A

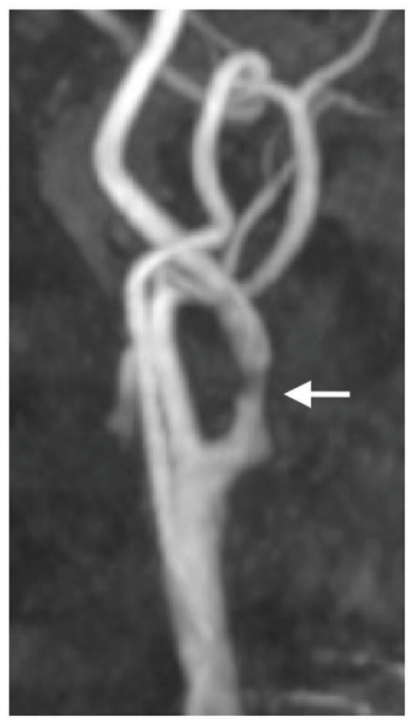

B

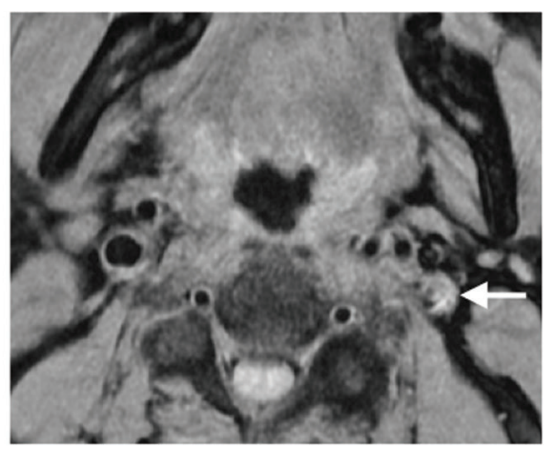

$\mathrm{C}$

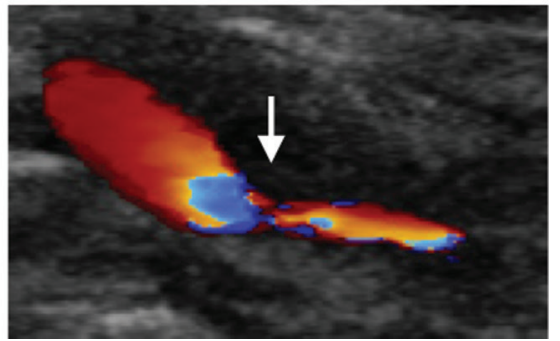

D

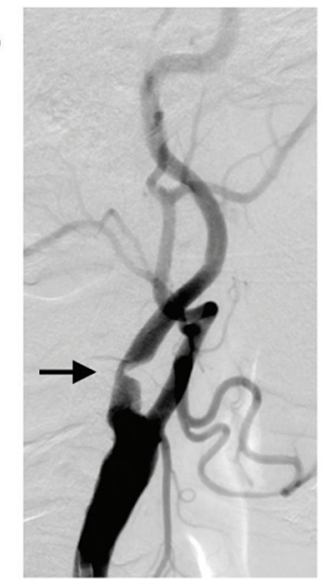

$\mathrm{F}$

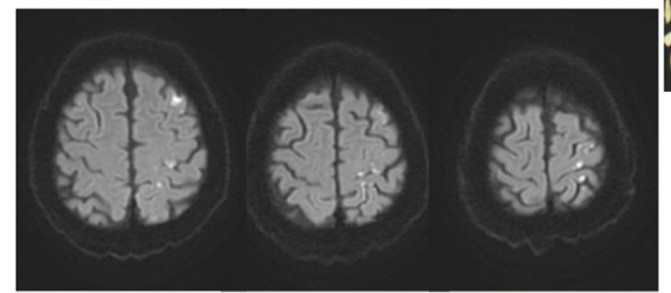

G

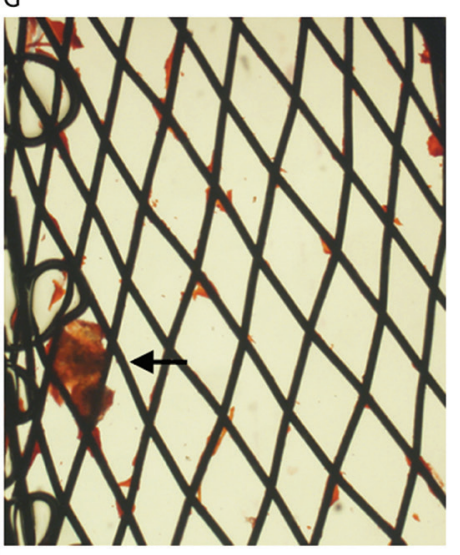

Fig. 4 Illustrative case. (A) MR angiography shows high-grade stenosis at the origin of the left ICA (arrow). (B) High-resolution MRI for the plaque evaluation shows high intensity on the T1 weighted image (arrow). (C) Ultrasound examination shows high-grade stenosis at the origin of the left ICA with echo-lucent plaque (arrow). (D) Preoperative control angiography shows high-grade stenosis at the origin of the left ICA (arrow). The stenosis is short segment. (E) Postoperative control angiography shows satisfactory dilatation of the stenosis. (F) Postoperative diffusion weight image of MRI shows multiple high-intensity lesions in the left cerebral hemisphere. (G) Microscopical filter observation shows organized debris captured (arrow). The fibrin precipitation is minimum. ICA: internal carotid artery 


\section{Case Presentation}

Complaint: Weakness of the right half of the body. Medical history: Hypertension (under treatment with an oral preparation).

Present illness: Transient weakness attacks of the right upper limb occurred twice. The patient consulted a local clinic. MRI did not reveal any abnormalities, but MRA showed stenosis of the left internal carotid artery (Fig. 4A). The patient was referred to our department.

Physical findings: The height, body weight, blood pressure, and pulse were $166 \mathrm{~cm}, 84 \mathrm{~kg}, 168 / 95 \mathrm{mmHg}$, and 80 beats/min (regular), respectively.

Neurologic findings: There were no abnormalities.

Imaging findings: On plaque diagnosis using high-resolution MRI, T1-weighted images showed a high signal intensity (Fig. 4B). Carotid ultrasonography revealed marked stenosis at the origin of the internal carotid artery. The maximum systolic blood flow velocity was $336 \mathrm{~cm} / \mathrm{second}$. Hypoechoic plaque was observed (Fig. 4C).

A diagnosis of a transient cerebral ischemic attack related to left internal carotid artery stenosis was made. The plaque was considered to be vulnerable, but stenosis involved a short segment, and the plaque volume was small; therefore, stenting with a filter was selected.

Endovascular treatment: Under local anesthesia, an $8 \mathrm{Fr}$ sheath was inserted into the right femoral artery. Heparin (3000 units) was intravenously injected so that the ACT was 270 seconds. An 8 Fr guiding catheter was inserted into the left common carotid artery. Angiography was performed to confirm marked stenosis of the left internal carotid artery (Fig. 4D). A Spider $5 \mathrm{~mm}$ was passed through the site of stenosis and deployed.

Using a balloon catheter measuring $4 \mathrm{~mm}$ in diameter and $20 \mathrm{~mm}$ in length, predilation was conducted at 6 atmospheric pressures. A Wallstent measuring $10 \mathrm{~mm}$ in diameter and $31 \mathrm{~mm}$ in length (Boston Scientific) was inserted into the internal to common carotid arteries. During this procedure, there was no flow impairment. The site of internal carotid artery stenosis was favorably dilated (Fig. 4E). The filter was collected, and the procedure was completed.

Postoperative course: Mild hemiparesis of the right upper limb was noted. The symptom reduced within 3 days. Diffusion-weighted MRI showed scattered high-signal intensities in the left cerebral hemisphere (Fig. 4F). When examining the filter, organized debris was observed (Fig. 4G). Fibrin adhesion was less. During surgery, there was no flow impairment or filter clogging. Therefore, cerebral infarction may have been related to debris passing through the filter.

\section{Discussion}

When performing carotid artery stenting, plaque-derived debris may appear on vasodilation or stent insertion, causing cerebral embolism; devices for preventing embolism are necessary. ${ }^{1,2)}$ Filters, balloons for blocking blood flow, and balloon guiding catheters are available, but filters can be simply handled while maintaining intraoperative blood flow; therefore, they are used as a first-choice device. In some institutions, several devices are combined.7) However, in Japan, only one type of device is covered by health insurance basically.

The filters were examined under a microscope to evaluate respective performance. Filter clogging may not occur when the filter area and volume are larger; the filter performance may be more favorable. Furthermore, the pore density is important for membrane-type filters. The area and volume of an AG were smaller than those of an FW, and the pore density was lower. Therefore, filter clogging may occur. If blood flow is reduced, fibrin formation may be induced, leading to flow impairment. In the AG group, fibrin precipitation was marked. If filter clogging occurs, there may be a space between the AG and vascular wall due to its octagonal blood-vessel-supporting surface, causing cerebral embolism through debris-containing blood leakage although the AG size can be selected in accordance with the vascular diameter. ${ }^{899}$ In all patients with cerebral infarction in the AG group, intraoperative flow impairment was noted.

Although the filter function of an $\mathrm{FW}$ is favorable, a size is matched to a vascular diameter of $3.5-5.5 \mathrm{~mm}$. In particular, this filter is relatively stressful for the vascular wall of fine blood vessels. According to a previous study, there was no filter clogging in patients with flow impairment under the use of an FW, suggesting vasospasm-related flow impairment. ${ }^{5)}$ In those cases, there was no association with cerebral infarction. For device-inserting/-removing procedures, careful operations may be necessary.

A Spider is a mesh-type filter, and the filter area and volume are relatively large. Therefore, filter clogging may not occur due to its structure. The size can be selected in accordance with the vascular diameter, and there may be no vasospasm-related flow impairment. In addition, secondary fibrin adhesion was minimum due to heparin coating. Structurally, a Spider is allowed to pass through lesions using a guidewire, and its derivability for markedly stenotic lesions is favorable. ${ }^{10)}$ However, the mesh size at the margin is $200 \mu \mathrm{m}$, being relatively large. In particular, soft debris may slip through the filter. For lesions evaluated as relatively fragile based on the results of plaque diagnosis, it may be necessary to select balloon occlusion devices. ${ }^{11,12)}$ 
A recent study assessed debris collected during carotid artery stenting, and confirmed that debris contained various components of plaque using immunostaining. ${ }^{13)}$ Furthermore, the volume of debris was more in hypoechoic plaques on preoperative ultrasonography. ${ }^{14,15)}$ Another study investigated biomarkers of debris, and reported that the expressions of interleukin-6, glycoprotein CD68, smooth muscle-actin, type IV collagen, and matrix metalloproteinase-9 were marked in symptomatic lesions. ${ }^{16)}$ Other studies indicated that debris containing inflammatory cells or a high level of a glucose metabolite, $\mathrm{N}^{\varepsilon}$-(carboxymethyl)lysine, was correlated with high-signal-intensity lesions on postoperative diffusion-weighted MRI. ${ }^{17,18)}$

Devices for preventing embolism may be necessary, but some studies did not demonstrate their efficacy ${ }^{19)}$ possibly due to in vivo responses to such devices, including fibrin formation, and adverse events, such as vasospasm. The risk of complex procedures with the combination of devices or non-routine procedures must be considered. If the duration of treatment is prolonged, responses, such as fibrin formation, may increase. It is also important to shorten the duration of treatment by standardizing or simplifying the procedure.

As the limitations of this study, open-cell stents were used in all patients in the AG group, whereas closed-cell stents were basically used in the FW and Spider groups; this may have influenced the results although filter selection depended on the timing of respective filter introduction, with no bias. According to previous studies, there were no differences in the properties or volume of debris related to the stent type or presence or absence of postdilation. ${ }^{15)}$

\section{Conclusion}

The characteristics of filters for carotid artery stenting differed between the membrane- and mesh-type structures. The results of treatment should be improved, understanding the characteristics of respective filters.

\section{Disclosure Statement}

There is no conflict of interest.

\section{References}

1) Brott TG, Hobson RW, Howard G, et al: Stenting versus endarterectomy for treatment of carotid-artery stenosis. N Engl J Med 2010; 363: 11-23.
2) Dumont TM, Rughani AI: National trends in carotid artery revascularization surgery. J Neurosurg 2012; 116: 1251-1257.

3) Hayashi K, Kitagawa N, Morikawa M: Observing the carotid debris aspirated during carotid stenting: technical note. Neurol Res 2005; 27: 22-26.

4) Hayashi K, Kitagawa N, Morikawa M, et al: Observation of the embolus protection filter for carotid artery stenting. Surg Neurol 2009; 72: 532-537; discussion 537.

5) Hayashi K, Horie N, Morikawa M, et al: Pathophysiology of flow impairment during carotid artery stenting with an embolus protection filter. Acta Neurochir (Wien) 2014; 156: 1721-1728.

6) Hayashi K, Horie N, Morikawa M, et al: [Identification of the debris collected during carotid artery stenting, comparing with carotid endarterectomy specimen]. JNET 2011; 5: 99-105. (in Japanese)

7) Miyachi S, Taki W, Sakai N, et al: Historical perspective of carotid artery stenting in Japan: analysis of 8,092 cases in The Japanese CAS survey. Acta Neurochir (Wien) 2012; 154: 2127-2137.

8) Casserly IP, Abou-Chebl A, Fathi RB, et al: Slow-flow phenomenon during carotid artery intervention with embolic protection devices: predictors and clinical outcome. $\mathrm{J} \mathrm{Am}$ Coll Cardiol 2005; 46: 1466-1472.

9) Roffi M, Greutmann M, Schwarz U, et al: Flow impairment during protected carotid artery stenting: impact of filter device design. J Endovasc Ther 2008; 15: 103-109.

10) Hayashi K, Matsunaga Y, Hayashi Y, et al: Observation method of the mesh-type embolus protection filter for carotid artery stenting. JNET 2017; 11: 592-596.

11) Hayashi K, Horie N, Morikawa M, et al: [Radiological study on the carotid plaque in Nagasaki University]. Jpn J Endovasc Intervent 2015; 16: 43-47. (in Japanese)

12) Sakamoto M, Taoka T, Nakagawa $H$, et al: Magnetic resonance plaque imaging to predict the occurrence of the slowflow phenomenon in carotid artery stenting procedures. Neuroradiology 2010; 52: 275-283.

13) Kambayashi Y, Yuki I, Ishibashi $T$, et al: Immunohistochemical analysis of debris captured by filter-type distal embolic protection devices for carotid artery stenting. J Stroke Cerebrovasc Dis 2017; 26: 816-822.

14) Giannakopoulos TG, Moulakakis K, Sfyroeras GS, et al: Association between plaque echogenicity and embolic material captured in filter during protected carotid angioplasty and stenting. Eur J Vasc Endovasc Surg 2012; 43: 627-631.

15) Piazza M, Squizzato F, Chincarini C, et al: Quantitative analysis and predictors of embolic filter debris load during carotid artery stenting in asymptomatic patients. $J$ Vasc Surg 2018; 68: 109-117.

16) Yang $M, Y u$ Y, Walsh WR, et al: A microscopic and biomarker evaluation of embolic filter debris collected 
during carotid artery stenting. J Endovasc Ther 2016; 23: 275-284.

17) Eto A, Sakata N, Nagai R, et al: $N^{\varepsilon}$-(carboxymethyl)lysine concentration in debris from carotid artery stenting correlates independently with signal intensity on $\mathrm{T}_{1}$-weighted black-blood magnetic resonance images. J Stroke Cerebrovasc Dis 2017; 26: 1341-1348.
18) Matsukawa H, Fujii M, Uemura A, et al: Pathology of embolic debris in carotid artery stenting. Acta Neurol Scand 2015; 131: 197-202.

19) SPACE Collaborative Group, Ringleb PA, Allenberg J, et al: 30 day results from the SPACE trial of stent-protected angioplasty versus carotid endarterectomy in symptomatic patients: a randomised non-inferiority trial. Lancet 2006; 368: 1239-1247. 